\title{
O discurso da moda catarinense: uma investigação da identidade através do viés histórico-cultural
}

\author{
The speech of Santa Catarina fashion: an investigation on identity through \\ historical-cultural bias \\ MORELLI, Graziela; Doutora; Univali \\ grazielamorelli@univali.br \\ CORREA, Ricardo Rodrigues; Bacharel; Univali \\ ricardo.correa@edu.univali.br
}

\section{Resumo}

Este trabalho busca definir e reunir elementos da identidade de moda catarinense. Através de uma pesquisa bibliográfica combinada a uma pesquisa de campo que, imersa no contexto histórico e cultural, procurou compreender a formação da atual identidade cultural de Santa Catarina, visto que se reflete diretamente em diversas áreas, inclusive na moda enquanto fenômeno social e industrial. No desenvolvimento da pesquisa foi possível compreender aspectos que formam a identidade da moda no âmbito regional, levantando seus pontos fortes, pontos fracos, desafios na contemporaneidade e a busca de soluções para problemáticas como as questões em torno da atuação do estado na produção de moda e sua visibilidade na criação.

Palavras Chave: moda; Santa Catarina; identidade.

\begin{abstract}
This work seeks to define and gather elements of fashion identity in Santa Catarina. Through a bibliographical research combined with a research that, immersed in the historical and cultural context, intended to understand the formation of the current cultural identity of Santa Catarina, since it is reflected directly in several areas, including fashion as a social and industrial phenomenon. In the development of the research it was possible to understand aspects that form the identity of fashion in the regional scope, raising its strengths, weaknesses, challenges in the contemporaneity and the search for solutions to problems such as the issues surrounding the state's performance in fashion production and Their visibility in creation.
\end{abstract}

Keywords: fashion; Santa Catarina; identity.

\section{Introdução}

Celebramos um século marcado pelo auge dos avanços tecnológicos e altos níveis de desenvolvimento, provocando um grande fluxo de circulação de informações que nos mantêm 
em conexão contínua. A moda é assimilada por Fogg (2013) como um reflexo do comportamento e, mudando em paralelo a este, vive-se um ciclo de transformações baseado naquilo que somos, também conhecido como identidade. Hall (1992) salienta que o homem pós-moderno vive uma crise de identidade pois, o indivíduo após ter uma identidade constituída, devido a intervenção de fatores como a globalização, está sofrendo a interferência de outras identidades, algumas vezes contraditórias e não-resolvidas, o que resulta em uma fragmentação da sua identidade original. Sendo a identidade de moda fruto da identidade cultural, faz-se necessário a investigação destes elementos visando a interpretação da forma como se apresenta.

O Brasil é um produtor de referências no âmbito cultural, onde Santa Catarina é integrante desse cenário multicultural, devido a colonização peculiar feita por várias etnias oriundas de diferentes lugares do mundo, que afetam de alguma forma o atual modo de vida, sobretudo o vestir, resultando em uma identidade de moda própria. Diante disso parte-se para problemática da pesquisa: como compreender a formação desta identidade através do prisma histórico-cultural? Procurando sinalizar caminhos que cheguem a uma resposta para esta indagação, o presente estudo tem como objetivo geral pesquisar a história e a cultura catarinense considerando os elementos que compõem a linguagem de moda do estado, bem como o seu posicionamento no mercado atual e direcionamento na posteridade contemporânea. Já os objetivos específicos são: levantar os pontos relevantes que culminaram na formação atual da identidade cultural catarinense; investigar o posicionamento da moda catarinense através de uma pesquisa de campo e compreender conceitualmente a identidade de moda feita em Santa Catarina. A relevância deste caminho de estudo justifica-se através da importância em ampliar a pesquisa em torno da cultura, da moda e demais assuntos correlatos no âmbito regional, além dos resultados aqui produzidos serem base e conteúdo para outras pesquisas que, por ventura, surgirem nas áreas do design.

\section{Uma breve abordagem histórica}

A humanidade vive uma busca incessante pela diferenciação de conceitos em torno das coisas e das pessoas. Tais conceitos, aliados a outras características, juntam-se para formar aquilo que essencialmente somos, ou seja, a identidade. Ciampa (1987, apud EMBACHER, 1996, p.57) afirma que "no seu conjunto, as identidades constituem a sociedade, ao mesmo tempo que são constituídas, cada uma por ela", ou seja, a formação da nossa identidade está sendo o tempo todo perpassada pelos eventos, pelo local, pelo tempo em que vivemos e pelas pessoas que passam pela nossa vida. Tudo, de alguma forma contribui para a revisão e transformação constante da nossa identidade. Da mesma forma, nós assim o fazemos também com tudo o que está ao nosso redor. Portanto, entendemos que, para interpretarmos fenômenos culturais da sociedade, faz-se necessário a compreensão da sua identidade, através do estudo de fatos históricos e posterior apontamento dos elementos que se reuniram para a formação do seu caráter atual.

A relação brasileira com a vestimenta tem início logo após o seu descobrimento quando, segundo Luz (2000), em 1503, os portugueses e espanhóis, iniciaram a extração de pau-brasil, enviando-o a Europa para ser uma das formas de tingimento de tecidos. Santa Catarina teve a sua colonização iniciada através do interesse de espanhóis e portugueses nas riquezas da região pois, após um naufrágio, navegantes teriam buscado abrigo no litoral que hoje correspondente ao estado (LUZ, 2000). 
O litoral catarinense possui como ponto forte da sua cultura atual, características da cultura portuguesa, em particular a açoriana. Este fato se deve a sua colonização que teve em cidades como Laguna, São Francisco do Sul, Florianópolis e Itajaí os maiores povoamentos formados por colonos vindos das ilhas portuguesas de Açores e Madeira ainda no século XVIII (LUZ, 2000). A similaridade do habitat litorâneo das ilhas portuguesas com o litoral catarinense, facilitou a adaptação do modo de vida e cultura dos ilhéus, resultando na vocação catarinense para o trabalho com atividades ligadas ao mar. Este fato permite a elucidação de alguns pontos da cultura catarinense, como a pesca ${ }^{1}$, culturas de mexilhões, comércio de produtos marinhos através dos famosos mercados públicos, artesanato, arquitetura, comidas típicas, folclore, turismo ligado ao mar e demais manifestações.

Um outro grupo de forte presença na constituição do povo e da cultura catarinense estava no território muito antes da chegada dos europeus: os índios. Os índios carijós recepcionaram os europeus na chegada em Santa Catarina sendo, segundo Luz (2000), dóceis e receptivos a catequese, parceiros de negócios nas trocas de mercadorias, aliados em combates e também formaram família com o homem branco, o que não impediu os abusos com a escravização e matança de muitos carijós em todo o território brasileiro.

Em Santa Catarina, tão marcada pela presença de múltiplas etnias, a cultura negra apresentase em segundo plano em relação às demais. Esse cenário se deve a muitos fatores, mas primeiramente, pelo fato de que a colonização catarinense é peculiar se comparada ao restante do país, pois teve o acréscimo de outros povos que dividiram o contexto social catarinense.

Em Santa Catarina a mão-de-obra escrava foi utilizada, segundo Pedro et. al (1988), para o uso doméstico, diferentemente de outras regiões que empregavam o trabalho escravo na produção agrícola. Também há registros consideráveis do uso do braço escravo nas armações baleeiras pois, segundo Cardoso e Schulz (2002), se instalaram em São Francisco do Sul e Imbituba, diversas armações para a pesca de baleia visando o abastecimento do mercado europeu.

A respeito dos imigrantes europeus que começaram a desembarcar no estado ainda na primeira metade do século XIX, é possível acrescentar uma série de elementos que nos ajudam a compreender características da identidade catarinense: o colono europeu trouxe consigo a sua profissão, fator determinante no desenvolvimento econômico do estado, pois eram mecânicos, ferreiros, tecelões, comerciantes, carpinteiros, operários e técnicos das mais variadas profissões. Nota-se que desde o inicio a colonização européia destacou-se no trabalho, utilizando das suas habilidades para o auxílio da construção do estado que temos hoje, inclusive para a consolidação da sua indústria.

Identifica-se também a vinda de colonos pertencentes a outros povos para Santa Catarina, acentuando ainda mais o caráter multicultural da sua identidade, pois sente-se em proporção menor, características dessas etnias na composição cultural catarinense. Segundo Cardoso e Schulz (2002), o estado recebeu colonos eslavos oriundos da Polônia e Rússia; árabes originários do Líbano e por fim observa-se a presença de famílias gregas, francesas, belgas e holandesas.

\footnotetext{
${ }^{1}$ De acordo com a Secretaria de Estado da Agricultura e da Pesca (2016), Santa Catarina é o maior produtor de pescado, mexilhões e ostras do país. Disponível em < http://www.sc.gov.br/agricultura-e-pesca $>$. Acesso em 24 de out. 2016.
} 


\section{Santa Catarina: celeiro de oportunidades}

O progresso catarinense rumo a atualidade teve início com a sua colonização que, segundo Hering (1987), partiu do transplante da cultura europeia para Santa Catarina. Esse processo funda-se na cultura e se reflete em todas as áreas do modo de vida catarinense, sendo a economia a primeira a ser afetada diretamente, já que a chegada do colonizador europeu trouxe a variação da atividade econômica, pois incentivou o surgimento da produção artesanal ou pequena indústria, como mercearias, fábricas de queijo e salame, sapatarias, marcenarias, fundições e etc. Esse processo criou o primeiro modelo de diferenciação social em Santa Catarina, pois na medida em que o comércio prosperava, o seu dono poderia pagar pela mãode-obra de outros colonos. Hering (1987) salienta que a viabilização da indústria partiu do crescimento das colônias, que demandavam produção agrícola e comércio maior e diversificado, gerando capital que, mais tarde, seria empregado na industrialização em diferentes áreas, o que justifica o bom posicionamento da atual economia do estado ${ }^{2}$.

A diversidade de atividades ganhou força no pós guerra entre 1945 e 1962, com o surgimento de novos setores, como a celulose, materiais elétricos, cerâmica e entre outros, além da ampliação dos setores já existentes como o têxtil e madeireiro. Este crescimento se manteve na década de 1980, com ressalvas de alguns setores que enfrentaram crises, mas que foram compensados pelo crescimento de outros.

Mais recentemente, observam-se alguns destaques oriundos de acontecimentos históricos, como a pecuária da região serrana, herança dos tropeiros que percorriam o território levando animais de São Paulo para o Rio Grande do Sul; a pesca, já praticada pelos índios carijós e aprimorada pelos colonos açorianos e madeirenses que colonizaram o litoral; a agricultura praticada pelas colônias europeias; e entre outros setores prósperos como o turismo, viabilizado pelos vastos recursos naturais presentes na paisagem catarinense. Esta e as outras fontes de renda permitiram a construção de uma economia forte e diversificada, conferindo aos catarinenses além das riquezas naturais do seu estado, também recursos financeiros que viabilizaram investimentos em muitas áreas, promovendo o desenvolvimento sociocultural em muitas frentes, refletidos em altos índices de $\mathrm{IDH}^{3}$ das cidades catarinenses e na constituição da sua identidade.

A contribuição da moda para a economia catarinense se reflete através da indústria têxtil, como a produção de malharia que, segundo Romero (1994 apud SANTOS, 2012), está presente na região do Vale do Itajaí, sendo líder estadual. Existem ainda pólos de jeanswear espalhados por todo estado, apontado por Santos (2012), em que a região de Criciúma e a cidade de Rio do Sul, no alto Vale do Itajaí, conhecida como capital catarinense do jeans, são referências estaduais na produção. $\mathrm{O}$ estado possui também a cidade de Ilhota que, de acordo com o Sebrae (2008), é conhecida como capital catarinense da moda íntima e moda praia, consolidada após as demissões da mão-de-obra ilhotense antes empregada no pólo têxtil de Blumenau e dispensada após as crises que se sucederam. Já outro destaque da indústria da moda catarinense é o pólo calçadista de São João Batista sendo, de acordo com o a Assintecal

\footnotetext{
${ }^{2}$ Segundo o IBGE (2013), Santa Catarina está entre as 6 maiores economias por estado no Brasil. Disponível em: http://www.ibge.gov.br/home/estatistica/pesquisas/pesquisa_resultados.php?id_pesquisa=5. Acesso em 24 de out. 2016.

3 Dados Censo 2010. IBGE - Instituto Brasileiro de Geografia e Estatísticas. Disponível em $<$ http://www.cidades.ibge.gov.br/xtras/uf.php?lang=\&coduf=42\&search=santa-catarina/>. Acesso em 26 de set. 2016 .
} 
(2016), o $4^{\mathrm{o}}$ maior produtor de calçado do país e tendo iniciado a sua produção por pequenos sapateiros que herdaram o ofício dos colonizadores europeus.

Apesar de haver uma movimentação significativa de outras frentes de produção dentro da indústria da moda catarinense, a indústria têxtil possui maior destaque. De acordo com a Sintex (2015), o estado corresponde a $27 \%$ da manufatura têxtil nacional, crescendo entre 2010 a 2014, cerca de $12,5 \%$ contra $3,5 \%$ da média nacional, sendo variada entre roupas e artigos de cama, mesa e banho. Essa força se reflete no fortalecimento do comércio através do atacado e varejo praticado pelas marcas e empresas de pequeno e médio porte, fazendo de regiões como a cidade de Brusque, seja um pólo de vendas de roupas, assim como Ilhota é pólo de venda de moda íntima e praia e Rio do Sul pólo de venda de jeanswear.

\section{A Indústria Têxtil}

A indústria têxtil catarinense é destaque no mercado nacional e internacional pela qualidade e pela força que exerce na economia regional, com destaque para as fábricas da região do Vale do Itajaí, que teve o seu início, sem o auxílio do governo, garantindo estabilidade através de recursos próprios (HERING, 1987). Ainda segundo Hering (1987), este processo bem sucedido teve início na colonização alemã que formou três grandes colônias: Joinville, Blumenau e Brusque. Todas começaram o seu desenvolvimento através da produção agrícola e pequenos comércios, mas evoluíram rapidamente devido ao seu modelo comunitário e trabalho incessante de seus integrantes. O emprego dos lucros obtidos no comércio viabilizaram o desenvolvimento da indústria têxtil, tendo o seu início em Blumenau, através da família Hering que possuía tradição no ramo têxtil ainda na Alemanha e por volta de 1878 , teriam se instalado no Brasil.

A vinda da família Hering para Santa Catarina foi crucial para o desenvolvimento da indústria têxtil no Vale do Itajaí, pois conforme Hering (1987), foi pioneira na importação de produtos a base de linho da Alemanha. Em seguida teria começado a produção própria com a costura de meias e produção em um tear de malharia. Mais tarde o baixo custo do fio de algodão em comparação com a importação de produtos prontos, teria impulsionado a produção de camisetas de algodão, já que o brasileiro assim como o alemão, tinha o hábito de usar camiseta de algodão por baixo das roupas.

Tendo como conceito "a moda que valoriza a sua essência" e o "lifestyle casual", 4 a marca Hering da atualidade manteve a produção de peças básicas do vestuário, o que demonstra a tradição seguida desde os seus primórdios, de acordo com o idealizado pelos seus fundadores. Outro fato importante que assegura o caráter empreendedor dos colonizadores e que se mantém até hoje na indústria catarinense foi a fundação da fábrica de tecidos Karsten e, logo depois outras indústrias como a Fábrica de Tecidos Carlos Renaux, fundada em 1892 na cidade de Brusque, reunindo tecelões alemães e poloneses, consolidando o Vale do Itajaí como potências no setor. Evoluindo ao longo das décadas, foram responsáveis pelo bom desempenho da economia catarinense, colocando o estado em um lugar de destaque no país neste setor ${ }^{5}$.

\footnotetext{
${ }_{5}^{4}$ Institucional. Cia Hering. Disponível em $<$ http://www.ciahering.com.br//>. Acesso em 26 de set. 2016.

${ }^{5}$ Sebrae - Serviço Brasileiro de Apoio a Micro e Pequenas Empresas. Site do SEBRAE. Disponível em $<\mathrm{http} / / /$ www.sebrae.com.br> . Acesso em 30 set. 2016. 
Porém, de acordo com Filho (2002), nos anos 90, o mercado têxtil brasileiro entrou em declínio devido a uma crise desencadeada pela abertura comercial que facilitou a entrada da concorrência internacional, fazendo com que as indústrias têxteis catarinenses tomassem medida drásticas e algumas declarassem falência. Este acontecimento marca a história da indústria têxtil catarinense, pois obrigou as fábricas a se adaptarem ao novo cenário que se apresentava: investimento em novas tecnologias, atualização do parque fabril, profissionalização e busca por estratégias que mantivessem o produto competitivo a altura do importado.

Os próximos passos são desafiadores, pois apontam caminhos com dificuldades e barreiras a serem superadas em um futuro que se aproxima. Em todas as fases dessa evolução, a indústria catarinense com seu espírito empreendedor soube se reinventar. Apoiada nos valores tradicionais e culturais, manteve-se firme perante as adversidades. É neste processo de apropriação e emprego dessas características próprias que podem nascer soluções para alguns dos problemas apontados.

\section{A identidade da moda catarinense: Um olhar contemporâneo}

O período contemporâneo trouxe para o âmbito regional alguns debates e situações presentes em escala global. No primeiro momento, a moda feita em Santa Catarina se adaptou ao modelo do fast fashion mundial, definido por Cietta (2010), como sendo um sistema industrial de produção e consumo de produtos de moda que segue tendências sazonais, focado na rapidez e baixo custo das peças. Porém, este modelo apresenta sinais de desgaste, em função de uma reflexão da sociedade sobre futuro que passou a questionar este processo pois, além da crise econômica global ${ }^{6}$, a moda tem alguns desafios no período contemporâneo, como a questão ambiental que permeia o processo produtivo e de consumo e o processo criativo volátil baseado apenas no emprego de tendências sazonais. Para Refosco, Oenning e Neves (2011), a sociedade passou a refletir sobre esse processo, pois a moda estaria passando por mudanças de foco, do valor monetário para a durabilidade, qualidade, design e meio ambiente.

O ciclo da indústria têxtil é altamente poluente demandando o uso de recursos naturais não renováveis. Segundo Moraes (1999), este ciclo é cercado pela geração de resíduos sólidos, efluentes líquidos, emissões de gases e entre outros. Tais fatos reforçam as recentes tendências de consumo lento, conhecido na moda pelo termo slow fashion, que é conceituado por Refosco, Oenning e Neves (2011), como um modo de desenvolver produtos pautados no equilíbrio entre o global e o local, focado na desaceleração dos processos, considerando o espaço sociocultural e ambiental, e sem o compromisso com grandes escalas produtivas. Podendo ser considerado uma filosofia que se reflete na economia e indústria, culmina na retomada de um consumo mais lento. Desta forma, percebe-se que o caminho do slow fashion é mais longo comparado ao do fast fashion, pois possui um ciclo diferente.

Além de uma das possíveis soluções para a questão ambiental, esse sistema vem reforçar a oposição aos produtos globalizados, pois outros movimentos sinalizam apoio ao movimento "slow" em outras áreas. De acordo com o Balston (2016), o termo "localismo" é uma tendência atual difundida na gastronomia que levanta a bandeira da defesa dos interesses

\footnotetext{
6 Portal de Notícias Online - $\quad$ BBC Brasil. $\quad$ Disponível em <http://www.bbc.com/portuguese/noticias/2016/02/160213_nova_crise_global_rc $>$ 6o GAMPI Plural, 2017, Joinville, SC.
} 
locais, através da utilização de alimentos da estação produzidos regionalmente, oferecendo resistência a produtos importados a partir da alegação de uma série de problemas como, por exemplo, pelo transporte do produto como aumento de preço e perda da qualidade. Este pensamento se aproxima do argumento de Dulci (2014), que consiste no fato de que a globalização não promoveu a homogeneização do mundo devido a fenômenos como o "localismo" que também pode ser observado em outras áreas que se colocam contra as tendências globalizantes.

Trazendo esse assunto para o contexto da moda, observa-se que o Brasil tem apostado no emprego da sua identidade na concepção de produtos para combater as questões apontadas. Fraga (2016) ressalta a importância da apropriação do patrimônio imaterial em prol do desenvolvimento de produtos, pois além da questão do mercado de moda impactado pela concorrência desleal de produtos importados, existe a preocupação com a criação de um produto autêntico que reflita a identidade e cultura local, pois as tendências globais tendem a criar uma atmosfera onde todos sinalizam o mesmo comportamento e comunicam as mesmas informações onde, ao deparar-se com esta figura refletida no espelho, torna-se complexo o ato de discernir quem somos.

$\mathrm{O}$ desafio de estar conectado em um mundo altamente globalizado e tecnológico, fazendo parte como um todo e ainda assim saber se diferir dos demais, com uma linguagem própria, é também um dilema confrontado com a moda catarinense. Segundo Fraga (2016), o estado se destaca pela qualidade da sua indústria têxtil, já que o próprio autor e estilista utiliza da matéria-prima catarinense em seus projetos, alegando a qualidade e tecnologia empregado no processo produtivo. No entanto, ainda está disperso no que tange aos elementos necessários para gerar o combustível que impulsione a composição de um produto autêntico e com um processo criativo autoral baseado nesta apropriação cultural. Percebe-se a necessidade da reunião de esforços entre a indústria, escolas de moda e sociedade em geral, para dar suporte às iniciativas que até existem no estado, mas que precisam ser melhoradas e incentivadas. Do contrário a identidade de moda catarinense viverá a contemporaneidade estando fadada apenas à reprodução de tendências globais, ignorando os vários pontos relevantes que poderiam ser melhor empregados e propagados, da vasta constituição da identidade cultural do estado já apontada em partes até então.

\section{As Escolas de Moda}

O histórico pioneiro da indústria têxtil catarinense, bem como a presença em áreas como o setor calçadista e moda praia, também atuante em Santa Catarina, demandou a profissionalização dos setores, através de investimento em mão-de-obra qualificada. Além de seguir a tendência do mercado, a contratação de um profissional do design de moda é uma ferramenta útil na composição e adequação do produto ao mercado. Essa demanda resultou na implantação dos cursos de Design de Moda e outros cursos ligados à área nas universidades catarinenses.

A UDESC ${ }^{7}$ implantou seu curso em 1996, sendo atualmente, de acordo com o Guia do Estudante (2016), o melhor curso de Design de Moda do país, tendo recebido conceito máximo com 5 estrelas, juntamente com o curso da Universidade Anhembi Morumbi de São

\footnotetext{
${ }^{7}$ UDESC - Universidade do Estado de Santa Catarina. Histórico do Curso de Design de Moda. Disponível em < http://www.ceart.udesc+.br/?id=263>. Acesso em 18 out. 2016. 
Paulo. Já a UNIVALI ${ }^{8}$ implantou o seu curso de Design de Moda em 2000 e possui classificação de 4 estrelas, de acordo com o Guia do Estudante de 2016. Sua localização é estratégica, próxima aos principais pólos têxteis do estado.

Tais fatos fazem de Santa Catarina, além de referência na indústria da moda, um centro de produção científica e de formação de profissionais da moda capacitados pelos melhores cursos do país. Estes elementos combinados formam no estado um cenário único e particular, com um campo vasto a ser explorado e potencial para ser um dos principais agentes produtores de moda no Brasil, o que em termos observou-se no decorrer deste trabalho, mas que ainda possuem questões que requerem debates e posicionamento de agentes que fazem a moda catarinense para a melhor compreensão.

\section{Pesquisa de Campo}

Para ilustrar e compor um panorama correspondente com a realidade, elaborou-se uma pesquisa de campo envolvendo o posicionamento de três profissionais atuantes na moda catarinense, pertencentes a academia e ao mercado: Suzana Lobo, graduada em Design de Moda pela Univali, especialista em Criação e Gestão de Produto de Moda pela Unifebe, participante de 2 edições do projeto SCMC, atuou como coordenadora de produto da RenauxView ${ }^{9}$ e atualmente dedica-se a direção criativa da sua marca Trendnauta, sediada em Itajaí - SC; Káritha Bernardo de Macedo, graduada em Moda pela UDESC, mestre em História pela UDESC, professora da área do vestuário no Instituto Federal Catarinense, membro do Grupo de Pesquisa Núcleo de Pesquisa em Moda e Tecnologia, do Instituto Federal de Educação, Ciência e Tecnologia de SC; e do Grupo de Pesquisa Moda e Sociedade da UDESC; Maristela Amorim, formada em Jornalismo pela UFSC, especialista em Moda pela Estácio de Sá, pioneira na criação de um caderno de moda para o jornal Diário Catarinense, conhecedora da área de cultura e variedades. As três profissionais foram entrevistadas por e-mail respondendo às mesmas perguntas que focavam no mercado de moda catarinense.

A primeira questão buscou os opiniões em torno da definição de uma identidade de moda catarinense. A pesquisa apontou que a identidade catarinense é composta por várias vertentes, como vocação industrial herdada da colonização europeia e os contrastes naturais do lifestyle litorâneo. A Indústria e o Mercado têm consciência da história e do passado e pesquisas em torno disso são importantes para o desenvolvimento de produtos de moda. Outro ponto de vista mostra que talvez não exista um conjunto que defina essa identidade, pelo menos não em regiões onde há a indústria têxtil forte como no Vale do Itajaí, em que as marcas são baseadas no fast fashion, não havendo investimentos no diferencial das peças. As marcas que seguem o caminho oposto têm um produto com preço elevado. A pesquisa mostrou que o posicionamento que foi construído no artigo em torno de design autoral, slow fashion e emprego da cultura e história no produto de moda está de acordo com a visão do mercado e da academia, pois a grande maioria da indústria de moda de Santa Catarina segue tendências do

\footnotetext{
${ }^{8}$ UNIVALI - Universidade do Vale do Itajaí. História do Curso de Design de Moda. Disponível em < http://www.univali.br/ensino/graduacao/ceciesa-ctl/cursos/design-de-moda/historia-docurso/Paginas/default.aspx>. Acesso em 18 out. 2016.

${ }^{9}$ Tradicional Indústria Têxtil de Brusque - SC, com mais de 90 anos, se destaca no mercado nacional, sendo matéria-prima para marcas e estilistas notórios da moda brasileira. Disponível em $<$ http://renauxview.com/site/historico.php>. Acesso em 21 out. 2016. 
mercado global, visando apenas as vendas. Este fechamento da indústria para propostas que sigam em caminhos diferentes é apontado como principal barreira no desenvolvimento de um produto de moda autoral que reflita a identidade catarinense.

$\mathrm{Na}$ segunda questão buscou-se visões sobre a realidade da moda autoral no mercado que acabou revelando que a moda autoral é pouco disseminada em Santa Catarina, pois está comumente associados aos consumidores excêntricos e alternativos, ficando restrita a pequenos grupos, feiras e sites específicos, pois na sua maioria, o mercado é voltado para o fast fashion. Ainda segundo a pesquisa, muitas marcas que levantam a bandeira do processo criativo autoral, fazem seu caminho por conta própria, através da redes sociais, território livre e democrático a todos os setores e marcas. Por outro lado a pesquisa aponta que o produto autoral demonstra a assinatura do criador e que neste contexto estão inseridos novas propostas de consumo e produtos locais artesanais. A pesquisa indica também caminhos para que a moda autoral catarinense percorra até a notoriedade, como eventos bem estruturados, investimentos do empresariado, universidades e outros envolvidos no setor, pois não basta apenas ter grandes cursos de moda, é necessário que todos somem forças na mesma direção, sobretudo a educação com o apoio das empresas.

A terceira questão da pesquisa propôs que os entrevistados emitissem opinião sobre o por quê de Santa Catarina não estar presente no hall de estados que conseguem transmitir sua identidade conceitual, autoral e autêntica no âmbito da moda, o que acabou revelando que o segmento dominado pelo estado catarinense na moda nacional tem sido em produtos comerciais que não representam a essência da identidade catarinense, pois são concebidos a partir de reproduções e releituras de produtos que lideram as vendas no Brasil e no mundo. As marcas que fazem o caminho contrário esbarram em questões arriscadas em relação aos lucros. Outro ponto destacado na pesquisa é o fato de que os estados destaques na moda nacional como um todo, possuem uma estrutura comercial e de marketing a favor, o que não é visto com tanto empenho em Santa Catarina. O êxito depende de uma série de fatores, sendo a divulgação dos pontos fortes, a melhor estratégia. A pesquisa cita como exemplo os cursos de moda catarinenses que estão entre os melhores do país e, no entanto, não possuem a visibilidade merecida. Grandes eventos de moda foram lembrados na pesquisa, como o Dragão Fashion (Ceará) e Minas Trend (Minas Gerais), pois são de grande importância no calendário de eventos no país e, no entanto, estão fora do eixo Rio - São Paulo, porém possuem uma grande estrutura envolvendo empresas, profissionais e influenciadores que proliferam as informações contribuindo para a montagem desses grandes palcos.

$\mathrm{Na}$ quarta questão a pesquisa voltou-se para o desafio de unir os fatos de se ter alguns dos melhores cursos de moda do país ao fato de se ter uma indústria potente, fazendo desses ingredientes uma única receita. Nesse sentido as entrevistadas revelaram que os profissionais precisam ser críticos em relação ao processo da moda, pois novas formas de consumo implicam em novas formas de produção, redirecionando o foco para a autoralidade, inovação e produção consciente. Novamente a pesquisa cita a importância da abertura dos empresários a novas propostas, do contrário a trajetória percorrida até aqui terá sido em vão. Citado como exemplo, o SCMC - Santa Catarina Moda e Cultura, é tido pelos entrevistados como passo importante para a integração da indústria com os estudantes de moda, porém ainda há muito o que fazer. A pesquisa confrontou o papel das escolas de moda em projetos autorais e na divulgação dos mesmos, pois elas devem ter além de bons cursos, vitrines que apresentem seus criadores como concursos, parcerias e eventos que aproximem todos os participantes desse processo. Com esta questão apontada pelos entrevistados, constata-se que além de ter os 
melhores cursos, a escola de moda deve adotar práticas que auxiliem na divulgação destes alunos através de concursos, parcerias e eventos que sejam vitrines para o mercado.

Por fim, os entrevistados foram questionados sobre o conceito da moda contemporânea catarinense e seus desafios como concorrência, desvalorização do artesanal e entre outros. A valorização da cultura regional direcionado ao design foi apontada como uma forma de desvencilhar-se de cópias. Investimentos financeiros, espaços de coworking, modelagens diferenciadas, pesquisa de moda, design de superfície e entre outros, são caminhos a serem seguidos apontados pelos entrevistados. Alguns bons exemplos de marcas catarinenses que brincam com o paradoxo comercial/autoral foram citados pela pesquisa, como a Von der Volke, Santa Costa, Empty e Lez a Lez que possuem, além da linha comercial, alguns produtos conceituais desenvolvidos em paralelo e com uma pitada do processo criativo autoral. Além disso, projetos como o Bazar Itinerante e a plataforma The Future, criada por Patricia Lima da Revista Catarina, que consiste no lançamento de tendências, eventos e ecommerce de marcas autorais, são lembrados pela pesquisa como incentivadores importantes para a moda contemporânea catarinense.

\section{CONSIDERAÇÕES FINAIS}

Ao término desta pesquisa pode-se fazer um panorama geral de tudo aquilo que foi apresentado, bem como alinhavar algumas conclusões. De acordo com os objetivos apresentados inicialmente, o trabalho procurou se aproximar de uma identidade de moda própria do estado, o que demandou percorrer alguns caminhos, como por exemplo o entendimento da identidade cultural do estado, através de fatos históricos. Sabe-se que Santa Catarina é um estado com uma pluralidade cultural ímpar devido ao seu peculiar processo de colonização composto por diferentes povos. Pode-se concluir que a atual identidade cultural do estado é composta por várias etnias, predominantemente europeia devido a fatos que transcorreram ao longo das décadas e séculos conforme apresentado nesse trabalho. Tal formação cultural se acentuou e influenciou diretamente o modo de vida atual da sociedade catarinense, transformando fatores sociais e econômicos.

Fruto da colonização europeia, a indústria têxtil catarinense demonstrou-se forte aos acontecimentos do tempo, contribuindo para o desenvolvimento das cidades e pólos produtores de tecidos, aviamentos e entre outros, pelo Vale do Itajaí e demais regiões, tornando esse sistema parte fundamental na moda catarinense. Por outro lado a pesquisa de campo revelou alguns pontos importantes da identidade de moda catarinense, pois como os entrevistados apontaram, essa identidade se apresenta dispersa em vários pontos e em outros baseada apenas na reprodução, não havendo espaço e criando dificuldades para aqueles que tentam conceber marcas e produtos com o processo criativo autoral. Pode-se observar alguns pontos positivos, pois a pesquisa mostrou que a indústria tem plena consciência das suas origens, no devido crédito à colonização europeia pela grandeza das empresas no mercado atual, o que, no entanto, não impediu que pontos negativos fossem identificados, pois esses elementos não são canalizados no sentido de construir um produto autoral com uma identidade autêntica catarinense. A pesquisa histórica, apesar de existir em alguns casos, não é extraída ao máximo o seu proveito no processo de criação.

Em relação ao futuro, a pesquisa foi categórica e esclarecedora, pois indicou possíveis caminhos até a concepção de uma moda contemporânea própria, através da inovação, investimentos de empresas, parcerias entre o ensino e empresas, valorização do artesanal e a 
apropriação do patrimônio cultural pela visão da moda com o intuito de olhar para dentro buscando essencialmente um produto que reflita aquilo que somos, aquilo que queremos que nos diferencie daqueles que nos cercam.

\section{REFERÊNCIAS}

ASSINTECAL. Associação Brasileira de Empresas de Componentes para Couro, Calçados e Artefatos. Assintecal São João Batista. Portal Online: 2016. Disponível em < http://www.assintecal.org.br/>. Acesso em 18 out. 2016.

BALSTON, Catherine. Localismo: a gastronomia do momento. Portal Último Segundo. São Paulo, 2016. Disponível em: <http://www.timeout.com.br/sao-paulo/ restaurantes/features/414/localismo-a-gastronomia-do-momento>. Acesso em 30 set. 2016.

CARDOSO, A.; SCHULZ, V. Formação Histórico-Geográfica de Santa Catarina. Tubarão: Copiart, 2002.

CIA. HERING - Institucional da Marca . Disponível em: < http://www.ciahering.com.br/novo/pt/empresa/negocio>. Acesso em 26 set. 2016.

CIETTA, Enrico. A Revolução do Fast-fashion: estratégias e modelos organizativos para competir nas indústrias híbridas. São Paulo: Estação das Letras e Cores, 2010.

COSTA, Maria Izabel. Projeto Santa Catarina Moda Contemporânea: uma dinâmica de cooperação entre instituições de ensino e empresas para o fomento do design catarinense. Modapalavra e-periódico. Florianópolis, ano 1, n.1, jan-jul 2008, pp. 77 - 86.

DULCI, Luciana Crivellari. Globalização Moda e a Cultura do Consumismo. $10^{\circ}$ Colóquio de Moda. Caxias do Sul, 2014. Disponível em: $<$ http://www.coloquiomoda.com.br/anais/anais /10-Coloquio-de-Moda_2014/ARTIGOS-DE-GT/GT09-MODA-E-GLOBALIZACAO/GT-9Globalizacao-Moda-e-a-Cultura-do-Consumismo.pdf>. Acesso em 30 set. 2016.

FOGG, Marnie. Tudo Sobre Moda. Rio de Janeiro: Sextante, 2013.

FRAGA, Ronaldo. Balneário Trends. In Balneário Camboriú Shopping. Balneário Camboriú, 14 set. 2016.

GOVERNO DO ESTADO DE SANTA CATARINA. Secretaria de Estado da Agricultura e da Pesca. Portal Online: 2016. Disponível em < http://www.sc.gov.br/agricultura-e-pesca $>$. Acesso em 24 de out. 2016.

GUIA DO ESTUDANTE - Curso de Design de Moda. Editora Abril: Portal Online, 2016. Disponível em $<$ http://guiadoestudante.abril.com.br/profissoes/design-de-moda/ $>$. Acesso em 18 out. 2016

HERING, Maria Luiza Renaux. Colonização e Industrialização no Vale do Itajaí. O Modelo Catarinense de Desenvolvimento. Blumenau: Editora Furb, 1987. 
IBGE - Instituto Brasileiro de Geografia e Estatísticas. Censo 2010. Disponível em $<$ http://censo2010.ibge.gov.br/>. Acesso em 13 de set. 2016.

\section{Produto Interno Bruto dos}

Municípios. Disponível em: <http://www.ibge.gov.br/home/estatistica/pesquisas/ pesquisa_resultados.php?id_pesquisa=46> Acesso em 21 de out. 2016

LUZ, Aujor Ávila da. Santa Catarina, Quatro Séculos de História: XVI ao XIX. Florianópolis: Insular, 2000.

PEDRO, J. et al. Negro em Terra de Branco: escravidão e preconceito em Santa Catarina no século XIX. Porto Alegre: Mercado Aberto, 1998.

REFOSCO, E.; OENNING,J.; NEVES; M. Da Alta Costura ao Prêt-à-porter, da Fast Fashion a Slow Fashion: um grande desafio para a moda. Modapalavra e-periódico. Florianópolis, ano 4, n.8, jul-dez 2011. Disponível em: $<$ http://www.periodicos.udesc.br /index.php/modapalavra/article/view/7808/5376>. Acesso em 30 set. 2016.

RENAUXVIEW. Têxtil RenauxView S/A. Histórico da Empresa. Disponível em < http://renauxview.com/>. Acesso em 21 out. 2016

SANTOS, Vanessa dos. Confecções de Jeans em Santa Catarina. In: $8^{\circ}$ Colóquio de Moda. Tubarão: UNISUL, 2012. Disponível em <http://www.coloquiomoda.com.br/anais/anais/8Coloquio-de-Moda_2012/GT10/COMUNICACAO-

ORAL/103943_Confeccoes_de_Jeans_em_Santa_Catarina.pdf>. Acesso em 18 out. 2016.

SEBRAE. Serviço Brasileiro de Apoio às Micro e Pequenas Empresas. Ilhota Capital da Moda Íntima. Portal Online: 2008. Disponível em: < http://www.sebraesc.com.br/newart/default.asp?materia=16080>. Acesso em 18 out. 2016.

SINTEX. Sindicato das Indústrias de Fiação, Tecelagem e do Vestuário de Blumenau. Indústria Têxtil de Santa Catarina, Perspectivas e Desafios para o Crescimento. Blumenau: Relatório Setorial, 2015. Disponível em $<$ http://www.sintex.org.br/arquivos/249_ap_sintex-2015_final.pdf $>$. Acesso em 18 out. 2016.

UDESC. Universidade do Estado de Santa Catarina. Histórico do Curso de Design de Moda. Portal Online, 2016. Disponível em $<$ http://www.ceart.udesc.br/?id=263 $>$. Acesso em 18 out. 2016.

UNIVALI. Universidade do Vale do Itajaí. História do Curso de Design de Moda. Portal Online, 2016. Disponível em < http://www.univali.br/ensino/graduacao/ceciesactl/cursos/design-de-moda/historia-do-curso/Paginas/default.aspx>. Acesso em 18 out. 2016. 